DOI: $10.35355 / 0000046$

\title{
ETNOGÊNESE E ESTRATÉGIAS TERRITORIAIS DO QUILOMBO DO ROSA, MACAPÁ/AMAPÁ
}

\author{
David Junior de Souza Silva* \\ Universidade Federal do Amapá - UNIFAP \\ davi_rosendo@live.com
}

\begin{abstract}
RESUMO: As comunidades quilombolas do Amapá iniciaram seus processos de etnogênese no início do século XXI. Este artigo objetiva refletir sobre o processo de etnogênese do Quilombo do Rosa. A metodologia de pesquisa baseia-se em etnografia realizada junto à comunidade. Para a produção da etnogênese em si, dois processos fundantes foram identificados: o primeiro, a mobilização, em 2002, contra uma mineradora, quando esta planejava depositar rejeito tóxico de mineração, nas terras da comunidade; o segundo, a implementação do Programa Brasil Quilombola. O universo simbólico e a autorrepresentação da comunidade são muito maiores do que a identidade que esta assume no contexto multiétnico de contato. Esta dimensão de sua identidade, a de remanescente quilombola, é levada a primeiro plano para viabilizar a comunicação com o Estado. A etnogênese, assim, tem o sentido de uma estratégia territorial, porém não resume todo o universo de significados da ancestralidade, memória e tradição da comunidade.
\end{abstract}

PALAVRAS CHAVE: Reconhecimento. Movimento quilombola; Direitos étnicos; Interculturalidade.

\section{ETHNOGENESIS AND TERRITORIAL STRATEGIES OF KILOMBO OF ROSE, MACAPÁ/AMAPÁ}

\begin{abstract}
The quilombola communities of the state of Amapá began their processes of ethnogenesis in the early 21 st century. This article aims to reflect on the Quilombo of Rosa ethnogenesis process. The research methodology is based on ethnography performed with the community. For the production of ethnogenesis itself, two founding processes were identified: the first, the mobilization in 2002 against a mining company, when it planned to deposit arsenic, toxic mining tailings, on community lands; the second, the implementation of the Brazil Quilombola Program. The symbolic universe and the selfrepresentation of the community is much larger than the identity it assumes in the multiethnic context of contact. This dimension of his identity, that of remnant quilombola, is taken to the fore to enable communication with the Brazilian national society. Ethnogenesis thus has the meaning of a territorial
\end{abstract}

Professor Adjunto do curso de Ciências Sociais da Universidade Federal do Amapá (UNIFAP). PósDoutorando no Programa de Pós-Graduação em História da Universidade Federal do Amapá PPGH/UNIFAP. Doutor em Geografia pelo Instituto de Estudos Socioambientais da Universidade Federal de Goiás (IESA/UFG). Mestre em Sociologia pela Universidade Federal da Grande Dourados (UFGD) 
Disponível em: www.revistafenix.pro.br

strategy, but it does not summarize the whole universe of meanings of community ancestry, memory, and tradition.

KEYWORDS: Recognition. Quilombola movement; Ethnic rights; Interculturality.

\section{INTRODUÇÃO}

Neste artigo, trato do processo de auto-identificação e de auto-reconhecimento da comunidade do Rosa como comunidade remanescente quilombola. Este tipo de processo tem sido tratado pela literatura sobre o tema como processo de reconhecimento identitário. Aqui, dou tratamento analítico ao processo por meio do conceito de etnogênese.

Pretendo demonstrar que o auto-reconhecimento identitário, a etnogênese, não se esgota em fins unicamente políticos; explica-se pela referência à ancestralidade africana e à condição escravizada no Brasil e pela referência ao território.

A certeza de sua ancestralidade africana e história escravizada no Brasil nunca foi objeto de dúvida para as comunidades de afrodescendentes. Entretanto, à medida em que movimento negro e quilombola conquistam nacional e internacionalmente o compromisso público e estatal com os direitos das comunidades tradicionais e com a dívida histórica da escravidão, um conjunto de direitos formando uma cidadania específica para estas comunidades foi estrutura no Estado. Para ter acesso à esta cidadania específica e usufruir dela, a comunidade tem de provar sua ancestralidade e sua especificidade étnica à estrutura jurídica do Estado, nos parâmetros em que este as compreende.

O recente processo de territorialização da comunidade do Rosa, aqui em pauta, tem por objetivo a defesa da própria existência, do território e do modo de vida da comunidade. Neste trabalho de defesa de si mesmos contra a territorialização e expropriação capitalista que avançava, a comunidade adotou, como parte da estratégia de defesa, o acionar do Estado contra os agentes violentos e expropriadores que a atingiam.

Esta estratégia de acionar o Estado pode ser no sentido de acionar seu arcabouço jurídico ou universal de ordenamento da sociedade, como Polícia Federal e Ministério Público; ou acionar as instituições políticas e jurídicas criadas especificamente para atender aos direitos étnicos, caso do departamento de regularização de territórios quilombolas do INCRA e da Fundação Cultural Palmares. 
Disponível em: www.revistafenix.pro.br

É aí que entra a etnogênese diretamente ligada ao território e ao modo de vida da comunidade, como estratégia territorial, como um dos passos possíveis e necessários para garantir a continuidade da comunidade e defendê-la de ações de fragmentação territorial realizadas por invasores. Assim, para compreender o processo de territorialização do Rosa é preciso compreender sua etnogênese como comunidade remanescente quilombola como uma das estratégias para territorialização.

Antes, uma palavra sobre o conceito de estratégia territorial aqui adotado. Para compreender esse conceito, é preciso entender dois de seus fundamentos: a configuração social colonial que impõe em primeiro lugar a necessidade de um dispêndio de energia em um trabalho ativo de defesa por parte de determinados sujeitos - que será conceptualmente nomeado aqui como resistência -; e as múltiplas relações entre resistência e território.

A resistência, o esforço para defender a própria vida e o direito de existir, tem sido uma condição - histórica, não ontológica - dos sujeitos e povos atingidos pelo poder e pela violência colonial. Único modo de vida possível em uma relação intersocietária que se move para sua escravização e seu genocídio completo.

Edir Pereira, realizando uma costura teórica de vários autores, relaciona a ação e condição da resistência ao território e à territorialidade.

Várias formas de resistência são praticadas por grupos sociais subalternizados. Muitas vezes, estas envolvem estratégias e táticas que são territoriais. Em grande parte, territorializar-se, desterritorializar-se e reterritorializar-se, ainda que com deslocamentos mínimos ou sem deslocamentos aparentes, são práticas socioespaciais de resistência de grupos sociais subalternizados constituídos na "ferida colonial". A resistência constitui-se em e constitui territórios e territorialidades. A resistência se espacializa, se territorializa, ainda que seja uma "territorialização precária" ou uma forma de escapar da "precarização territorial" como tem sido para a maior parte da população do mundo moderno-colonial. (PEREIRA, 2017, p. 19)

Conforme o autor, "territorializar-se, desterritorializar-se e reterritorializar-se" passam a ser ajustes ou ações, enfim estratégias para fazer frente a ações de violência ou expropriação por outros atores.

$\mathrm{O}$ ato e trabalho de resistência vincula-se ao e produz um território, porém, dadas as condições do fazer político contemporâneo, não pode se restringir ao território 
nem ser feita somente de dentro dele. A multiterritorialidade é uma exigência para o trabalho de defesa territorial e de resistências em geral na contemporaneidade.

A multiterritorialidade é lembrada pelo autor como característica inerente às ações de resistência, defesa de si, do próprio modo de vida e do próprio direito de existir.

Quem resiste constrói um território de resistência. Resistir não é se fechar num território ou, a todo custo, tentar proteger um território apropriado e/ou próprio. Pelo contrário, resistir envolve, atualmente, acionar e acessar territórios múltiplos. A resistência joga com estratégias e táticas de multiterritorialidade. (PEREIRA, 2017, p. 19)

O sentido de resistir nesses casos é recuperar e defender a própria autonomia em sociedades não democráticas e violentas. A autonomia é a possibilidade de viver sem interferência violenta de outrem, de viver conforme seu modo de vida e de decidir seu futuro.

Em torno deste núcleo de reflexão, as estratégias territoriais são as ações concretas que realizam concretamente a territorialização e garantem o território.

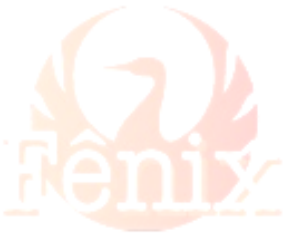

Estratégias territoriais são modalidades de práticas socioespaciais ou apenas práticas espaciais que formam as ações estratégicas constitutivas do processo de territorialização dos diferentes grupos sociais. Existe uma multiplicidade de práticas socioespaciais que constituem o processo de territorialização dos agentes sociais, algumas destas são estratégicas. Um conjunto mais ou menos coerente ou coordenado de estratégias territoriais constitui o que podemos chamar de "exercício espacial do poder" e/ou da resistência, dentro de uma sociedade ou grupo social, em determinado período de tempo e em determinado espaço. Quando as estratégias territoriais se articulam, no exercício espacial do poder/resistência, o fazem por meio de "tecnologias do poder", com dispositivos estratégicos territoriais. (PEREIRA, 2017, p.40).

As estratégias territoriais assim são um tipo específico de práticas socioespaciais. Distinguem-se por serem práticas que constituem o processo de territorialização dos sujeitos. Para o caso do Rosa têm importância decisiva, pois, no período estudado, a comunidade procura configurar um novo processo de territorialização. Nesse sentido, as estratégias territoriais ganham importância, porque estão atuando para criar e estabelecer o novo.

Uma destas estratégias territoriais assim, nominada desse modo porque ajuda a configurar o novo território, é a etnogênese, o processo de trazer para o primeiro plano, o da identidade e da comunicação, a ancestralidade africana e o passado escravo, para 
Disponível em: www.revistafenix.pro.br

comunicar- se, interagir e fazer-se compreender e reconhecer na situação multiétnica de contato.

\section{ETNOGÊNESE DENTRO DO NOVO PROCESSO DE TERRITORIALIZAÇÃO}

A etnogênese como estratégia política e territorial para a comunidade do Rosa aparece como possível no contexto da compreensão mundial contemporânea do que são as comunidades tradicionais - expressa por exemplo na convenção 169 da OIT -, incluso os quilombos, da legislação internacional decorrente desta compreensão, da legislação brasileira sobre direito quilombola, produto da síntese entre legislação internacional e ativismo negro e quilombola nacional, e do trâmite real do processo jurídico e burocrático para acesso à cidadania quilombola no contexto nacional brasileiro e regional amazônico e amapaense - este trâmite sendo por seu turno síntese da relação de forças travada na sociedade brasileira contemporânea, na qual atuam, dentre outros elementos, o racismo, a luta pela terra, as personificações do capital interessadas na mercantilização da terra, movimento negro e movimento quilombola, e a luta diária cotidiana das comunidades tradicionais pelo direito à vida e à própria reprodução social.

Nesta seção, analiso os fatores envolvidos no processo de etnogênese do Quilombo do Rosa. Para a produção da etnogênese em si, dois processos fundantes foram identificados. O primeiro, a mobilização, em 2002 contra a mineradora ICOMI, quando esta planejava depositar arsênio, rejeito tóxico de mineração, nas terras da comunidade. O segundo, a chegada de uma política pública, o Programa Brasil Quilombola. Na fala da comunidade sobre sua etnogênese, não está presente com frequência o assassinato do patriarca da comunidade. Este silêncio, todavia, pode ser justa evidência da importância desta fala na transformação da comunidade.

Como expressão das contradições presentes no processo de etnogênese, o Rosa teve de enfrentar a resistência interna à auto-identificação como quilombola por alguns membros da própria comunidade; resistência superada pelos processos de produção de consenso próprios do grupo. Está ainda somente na fala e ação de moradores da vila “emprestados” (não pertencentes à comunidade), contrários à titulação do território como quilombola. 
Disponível em: www.revistafenix.pro.br

A força motriz decisiva para a intencionalidade da comunidade do Rosa em direção ao auto-reconhecimento como quilombola e o amparo respectivo da lei foram as ameaças reais ao território da comunidade, experienciadas no período. No que concerne à relação entre etnogênese e território, o auto- reconhecimento como quilombola e o posicionamento público como tal foi decisivo para assegurar o território do grupo face estas ameaças externas do período.

\section{ETNOGÊNESE E TERRITÓRIO}

As etnogêneses são os processos de construção identitária nos quais os povos tradicionais constroem-se como sujeitos coletivos com base em uma tradição cultural preexistente, objetivando sustentar a ação coletiva e a mobilização por direitos. Este fenômeno foi até agora estudado relativamente aos povos indígenas; todavia, é um fenômeno que vivem também as comunidades quilombolas.

As comunidades remanescentes quilombolas no Amapá, com exceção do Quilombo do C-riaú, iniciam processos de etnogênese no início do século XXI. Este artigo objetiva compreender os fatores envolvidos no processo de etnogênese do Quilombo do Rosa.

Conforme teorizado pelo antropólogo mexicano Miguel Alberto Bartolomé (2006), as etnogêneses tratam-se de processos protagonizados pelos povos nativos no qual se reapropriam de sua identidade étnica, uma vez tendo sido obrigadas a abandonar esta identidade nos processos de colonização. Nas palavras do autor, "Trata-se da dinamização e da atualização de antigas filiações étnicas às quais seus portadores tinham sido induzidos ou obrigados a renunciar, mas que se recuperam combatentes, porque delas se podem esperar potenciais benefícios coletivos" (BARTOLOMÉ, 2006, p. 40).

Sua natureza de processo social, cultural e identitário é evidente; porém é distintivo também seu conteúdo político: a "etnogênese apresenta-se como processo de construção de uma identificação compartilhada, com base em uma tradição cultural preexistente ou construída que possa sustentar a ação coletiva" (BARTOLOMÉ, 2006, p. 44).

É, pois, a reapropriação de uma identidade, com vistas à sustentação da ação coletiva, em geral frente ao Estado. Neste processo os povos nativos objetivam "se 
Disponível em: www.revistafenix.pro.br

constituírem como coletividades, como sujeitos coletivos, para poderem se articular ou se confrontar com seus Estados em melhores condições políticas” (BARTOLOMÉ, 2006, p. 44).

A propulsão do processo pode estar, já prevista por Bartolomé, na existência de novas legislações, que garantem atualmente direitos antes negados. "Em certas oportunidades isso se deve à desestigmatização da filiação nativa, mas frequentemente também às novas legislações que conferem direitos antes negados, como o acesso à terra ou a programas de apoio social ou econômico" (BARTOLOMÉ, 2006, p. 45).

No caso das comunidades remanescentes quilombolas brasileiras, as políticas públicas oficiais de reconhecimento de comunidades remanescentes quilombolas, notadamente o Programa Brasil Quilombola, no Brasil no início do século XXI, desempenharam papel de primeira importância para a etnogênese do Rosa e de outras comunidades quilombolas do Amapá - o que não quer dizer necessariamente que não ocorreriam de outra maneira.

Para caracterizar esta relação no Brasil contemporâneo, do movimento social quilombola com o Estado, o direito e as políticas públicas, Amanda Lacerda Jorge (2015) define a condição do movimento social quilombola no Brasil como realizando um "caminho inverso":

Isto porque, até a existência do dispositivo constitucional em 1988, tal movimento era incipiente e não se articulava prioritariamente a partir da denominação 'quilombola'. Neste sentido, o artigo 68 do ADCT abriu o caminho para que esse movimento nascente ganhasse robustez e trilhasse novos caminhos, com o fortalecimento de suas reivindicações. (JORGE, 2015, p. 146)

Inclusive na reapropriação da identidade étnica quilombola - isto é, na etnogênese. Muitos/as militantes estavam nos movimentos negros e/ou rurais. Se reconheciam negros e ligados ao passado africano e ao histórico de escravismo e liberdade (RATTS, 1996). Muitas comunidades eram denominadas de "terras de pretos" ou expressões semelhantes.

Para análise do processo em pauta aqui, a produção da etnogênese, distinguimos os processos fundantes, que são facilmente localizáveis, e processos de consolidação. Igualmente, identificamos também que etnogênese não é um evento, mas um processo, longo no tempo, repleto de dialeticidades, de idas e vindas. 


\section{A PRODUÇÃO DA ETNOGÊNESE}

Antes de entrarmos propriamente nos fatos históricos particulares próprios da história do Rosa que produziram sua etnogênese, devemos situar os elementos contextuais macro-históricos e globais que contribuíram para a etnogênese do quilombo.

Estes elementos de diferentes escalas, oriundos da agência de outros atores sociais e outros processos históricos, deram condição de possibilidade para a etnogênese do Rosa e forneceram boa parte de sua semântica e de sua sintaxe, à medida em que a comunidade foi convocada - e teve que se sujeitar - a aderir à linguagem disponibilizada e exigida pelas instâncias da esfera pública detentoras do poder de legislar sobre a questão e conferir o acesso aos direitos universal e regionalmente conquistados e estabelecidos, e pelo campo intelectual e simbólico envolvido na disputa simbólica sobre a temática. São eles a Convenção 168 da Organização Internacional do Trabalho, do ano de 1988; a Constituição da República Federativa do Brasil, de 1988, especialmente os artigos 216 e 217, bem como o Ato das Disposições Constitucionais Transitórias; e, mais recentemente, o Programa Brasil Quilombola, de 2003.

Direitos construídos e conquistados na mobilização internacional por direitos das comunidades tradicionais, sua incorporação no Direito Constitucional brasileiro, e sua materialização em políticas públicas fazem parte do contexto político, simbólico e jurídico que fez parte da etnogênese do Rosa como comunidade remanescente de quilombo, no Amapá no início do século XXI, devendo ser considerados analiticamente como marcos da etnogênese do Rosa.

Marcos para a etnogênese do Rosa foram a garantia do direito na Constituição de 1988, o ADCT 68, que impulsionou a auto-identificação o reconhecimento social público das comunidades quilombolas no Brasil; a criação de políticas públicas com vistas materializar este reconhecimento. Na esfera da história particular da comunidade, a mobilização empreendida pela comunidade contra a mineradora que intencionava depositar rejeitos tóxicos de mineração em seu território, e a defesa contra um morador que estava vendendo terras da comunidade, foram fatores que desencadearam a busca por respaldos eficazes e mais fortes para defesa do território e da vida da comunidade.

A título de contextualização, sobre as políticas públicas favoráveis, no estado do Amapá, estas políticas propiciaram o início do processo de reconhecimento de uma 
Disponível em: www.revistafenix.pro.br

quantidade considerável das comunidades quilombolas no estado, algumas vindo a fechar o ciclo, com a titulação definitiva de suas terras, como é o caso das comunidades Conceição do Macacoari, Mel da Pedreira e São Raimundo do Pirativa. A exceção fica por conta do Quilombo do C-riaú, cujo processo de reconhecimento, certificação e titulação ocorreu na década de 1990.

Analiticamente, distingue-se aqui os eventos fundantes ou que dispararam a etnogênese do Rosa, daqueles que vieram na sequência e tiveram o efeito de consolidar esta etnogênese.

\section{EVENTOS FUNDANTES}

Para a produção da etnogênese em si, quatro processos históricos fundantes foram identificados.

O primeiro, a mobilização, em 2002 contra uma mineradora, a ICOMI Indústria e Comércio de Minérios S.A., quando esta planejava depositar arsênio, rejeito tóxico de mineração, nas terras da comunidade.

Diante da ameaça da ICOMI a comunidade do Rosa articulou-se com outras comunidades quilombolas, acionou a prefeitura municipal, acionou uma deputada federal, acionou outras comunidades da região, e realizaram uma grande mobilização que durou uma semana, na qual lograram expulsar a empresa do local e frustrar seus planos de despejar os rejeitos no território da comunidade.

Esta mobilização, malgrado não tenha trazido ainda a identificação como quilombola para a comunidade, acentuou fortemente seu sentido de comunidade, e interpôs na consciência da comunidade a certeza da necessidade de defender-se. Em 2002, aconteceu esse que foi um dos episódios marcantes da fundação da nova territorialidade do Rosa e de sua etnogênese como quilombo: a luta contra ICOMI e a defesa contra a ação de $\mathrm{N}$.

Estes dois processos contribuíram, evidentemente, também para a configuração identitária do Rosa, naquilo que deve ser o mais evidente nesse escopo: na produção de um forte sentido de comunidade. Todavia, há um fator ao qual não pode não ser ligada a produção da identidade de comunidade remanescente quilombola: a implementação do Programa Brasil Quilombola, o qual trouxe a categoria jurídica e a categoria identitária de remanescente quilombola. Este é o terceiro processo. 
A identidade de comunidade remanescente quilombola não pode não ser ligada à existência desse programa. Este programa, realizado por meio do INCRA, foi que trouxe a categoria jurídica e identitária de remanescente quilombola, com a qual a comunidade se identificou atrelando-a a seus antecedentes ex-escravos.

O Programa Brasil Quilombola é uma política pública do governo federal para as comunidades negras rurais, com o objetivo de propiciar as condições para o autoreconhecimento destas comunidades como remanescentes quilombolas e o consequente acesso aos respectivos direitos.

Criado em 2003 na esfera federal, o programa chegou ao Amapá em 2004, através do INCRA local. Na ocasião a superintendência do INCRA se encontrava sob gestão de Cristina Almeida, conhecida militante do movimento de mulheres negras local.

Até então a única comunidade quilombola que havia no estado era o Quilombo do C- riaú - que foi nada menos do que o segundo quilombo a ser titulado no Brasil. Cristina Almeida, na condição de superintendente do INCRA, atuou, na esteira do Programa recém- criado, no sentido de difundir os direitos quilombolas às comunidades negras rurais do estado e assim incentivar o auto-reconhecimento e a titulação. A presença desta militante do movimento de mulheres na direção do INCRA pode ser localizado como fato autônomo de contribuição para o processo em pauta.

Assim se expressa Geralda sobre a chegada do Programa Brasil Quilombola ao Rosa.

O pessoal do INCRA vinha e conversava muito com a gente sobre o que é ser quilombola. Traziam mapas, ficavam explicando os mapas pra gente. A gente aceitou porque a gente precisava de uma força a mais. Então tornar-se quilombola foi bom para dar essa força a mais para defender-se contra ameaças [que naquele momento eram ICOMI e N].

Até então, conforme Joelma Meneses, havia certo misticismo, como ainda há hoje, em relação à categoria jurídica quilombola e ao tornar-se quilombola. Segundo ela, "o pensamento de muitos é 'eu vou virar quilombola, não vou poder fazer isso, não vou poder aquilo"”. Havia, portanto, razoável desconhecimento quanto ao direito quilombola e desconfiança quanto ao ser e tornar-se quilombola.

Nas palavras de Joelma, o auto-reconhecimento como quilombola e o posicionamento público como tal foram decisivos para assegurar o território do grupo 
face estas ameaças externas do período. Especialmente o episódio protagonizado por ICOMI e N.

A comunidade avaliava, assim, que havia possibilidade real e presente de perder as terras, principalmente por conta do ocorrido com a ICOMI. Este evento foi mesmo disparador da intencionalidade e da ação do grupo em direção à demarcação do território, como garantia contra estas ameaças.

Auto-identificar-se como quilombola, assim, ou atualizar a identidade de remanescente de quilombo, significou o que Bartolomé coloca em sua análise como constituição "como coletividades, como sujeitos coletivos, para poderem se articular ou se confrontar com seus Estados em melhores condições políticas" (BARTOLOMÉ, 2006, p. 44).

Sobre a relação do Rosa com as outras comunidades, no exame da possível influência do movimento por reconhecimento e demarcação das outras comunidades sobre a etnogênese e nova territorialização do Rosa, Joelma aponta que esta influência veio de outra fonte - e não, neste momento, de uma possível influência recíproca entre comunidades.

A atuação no cargo de superintendente do INCRA de uma reconhecida militante do movimento de mulheres negras foi assim decisiva para a difusão do conhecimento sobre o direito quilombola no estado e para o incentivo às comunidades de iniciar o processo de titulação.

Joelma ressalta a diferença no trâmite do processo de titulação no início do Programa e atualmente:

Cristina deu tudo o que minha mãe precisava fazer. E não era tão burocrático como hoje. Precisava só a assinatura da comunidade. Então a gente fez. Essa burocracia de hoje é para atrapalhar. Nunca ajuda só atrapalha.

A ameaça real de perda do território e o apoio de uma militante negra no exercício de um cargo público neste momento estratégico foram decisivos para a etnogênese quilombola do Rosa.

Portanto, a chegada desta política pública, o Programa Brasil Quilombola, não obstante sua importância decisiva, precisa ser relativizada: sozinha não produziria o efeito que teve, sem a atuação das lideranças do movimento negro local - o quarto fator na etnogênese do Rosa. 
Sobre a confiança do Rosa e das demais comunidades em Cristina, é possível identificar que esta confiança vem de longa data. Geralda conta sua família e de Cristina eram muito próximas desde a infância. A confiança na figura de Cristina Almeida, na legitimidade de sua atuação e em seu compromisso com a causa quilombola, advém de uma proximidade anterior de razoável duração, que inclui vínculos de parentesco e ações políticas concretas.

Conforme Joelma, família da Cristina tinha terreno no quilômetro 21 (nas vizinhanças do Rosa). Cristina sempre fez parte do IMENA - Instituto de Mulheres Negras do Amapá, organização da sociedade civil, criada no ano de 2002, atuante sobre o tema da relações étnico-raciais, e que sempre fez trabalhos junto às comunidades negras, incluso do Rosa. Conforme Joelma, "elas [do Imena] não falam que são quilombolas, mas são mulheres negras”. A distinção que aparece como sinonímia nas palavras de Joelma evidencia não uma estreita ligação entre movimento negro - pelo qual deve se ler o movimento de mulheres negras - e movimento quilombola no Amapá; mas evidencia a conexão interna entre um e outro; uma relação de imanência.

Josielson descreve a atuação comprometida de Cristina na superintendência do Incra e procurando efetivar o Programa Brasil Quilombola.

Cristina, na superintendência do INCRA, organizava palestras e reuniões das comunidades, para esclarecimento sobre o direito quilombola; produzia cartilhas explicativas; quando tinha alguém de Brasília na cidade, levava nem que fosse uma meia hora só fazer uma fala nas comunidades. Deixava recado nas comunidades quando haveria audiência no INCRA e solicitava para a comunidade comparecer. Alguém da comunidade ia, chegava lá era alguém do Incra de Brasília fazendo uma fala e ouvindo as falas da comunidade. Para o INCRA nacional sempre saber o que estava acontecendo no Amapá.

A atuação do movimento negro regional - novamente, leia-se: o movimento de mulheres negras - deve ser colocado como uma das causas imediatas da etnogênese do Rosa.

O Programa Brasil Quilombola na prática é o Estado como promotor ou disparador de uma territorialidade específica. Lembrando que o Programa só existe graças ao movimento negro nacional. Desse modo, como conquista, o movimento negro nacional é o responsável pela propulsão desta territorialidade, bem como pela criação das condições da possibilidade de sua propulsão. Esta territorialidade disparada é 
Disponível em: www.revistafenix.pro.br

conquista do movimento negro nacional. A visão de mundo de onde emana ou o propulsor desta racionalização é o movimento da ética antirracista.

A etnogênese carrega significativa imponderabilidade do ponto de vista dos que a vivem. O futuro é tempo da incerteza. Atuar com consequências tão expressivas para o futuro da comunidade é sempre um risco. É atuar sem referências por onde situar a própria ação, atuar no espaço do inexistente, onde a ação territorializadora tem de ser a da criação.

Todavia, mesmo com a informação disponível e com a atuação de lideranças parceiras, a assunção como quilombola é um passo na incerteza para a comunidade. Envolve risco e coragem para arriscar entrar num campo desconhecido. Sobre o passo decisivo em direção ao auto-reconhecimento como quilombola. Josielson assim o define:

\begin{abstract}
Não sabíamos as consequências, são sabíamos o que ia dar, mas entramos de cabeça. Muitas pessoas militavam, pessoas que tinham respeito, renome, defendiam essa bandeira, militavam por esses ideais. Pessoas boas. Isso ajudou a não ter dúvidas. Ainda mais que quem estava à frente coordenando tudo era a Cristina, que veio pessoalmente nas comunidades. Ela sonhava com uma coisa além do que ela podia. Lá na frente ela não sabia o que podia acontecer.
\end{abstract}

A atuação militante e comprometida de pessoas, portanto, que tinham prestígio e legitimidade entre as comunidades foi fator importante nesse momento crucial de resolução da dúvida quanto a iniciar o processo o processo de auto-reconhecimento.

Nesta seção busquei mapear e analisar os elementos envolvidos no processo de etnogênese do Rosa. Na seção seguinte, analiso o desenvolvimento dessa etnogênese no tempo.

\title{
CONSOLIDAÇÃO (OU CONSOLIDAÇÕES) DA ETNOGÊNESE
}

A etnogênese não é um evento, mas um processo, longo no tempo, e repleto de dialeticidades. Para a consolidação, pois, da identificação como quilombola, outros processos atuaram. Cabe citar dois especificamente: a elaboração do mapa cartográfico da comunidade, realizada em parceria com a Universidade Estadual do Amazonas; a certificação do Rosa como comunidade remanescente quilombola, pela Fundação Palmares. 
Disponível em: www.revistafenix.pro.br

Estes dois processos contribuíram até o momento para a consolidação da etnogênese, ou seja, da auto-identificação e do reconhecimento da comunidade do Rosa como comunidade remanescente quilombola.

Sobre a elaboração da cartografia, cabe acrescentar algumas palavras apenas sobre o primeiro: a realização do mapa cartográfico da comunidade, em 2013, em parceria com a Universidade Federal do Amazonas, no Projeto Nova Cartografia Social da Amazônia.

$\mathrm{Na}$ ocasião, a comunidade foi convidada a realizar uma cerimônia de lançamento também na Assembleia Legislativa. Nesta ocasião, a comunidade denunciou as invasões e conflitos decorrentes que estava sofrendo em seu território. A projeção alcançada por estas denúncias levou as autoridades a tomar medidas imediatamente em relação a tais conflitos.

\section{ANTAGONISMOS INTERNOS AO TERRITÓRIO}

O processo da etnogênese não é homogêneo nem puramente consensual. É um processo dialético, e não raro conflitivo, no interior das comunidades, e assim também para o Rosa.

Como expressão das contradições presentes no processo de etnogênese, o Rosa teve de enfrentar a resistência interna à auto-identificação como quilombola por membros da própria comunidade; resistência em parte vencida, pelos processos de produção de consenso próprios do grupo, em parte presente ainda hoje, na consciência de moradores da comunidade ainda contrários à auto-identificação e titulação do território como quilombola.

Dentro do território do Rosa há ainda hoje a figura de N, uma pessoa especificamente que não quer ser quilombola, e que age no sentido de tentar influenciar as outras. Não quer ser quilombola porque tem interesse em vender os terrenos que ocupa dentro da comunidade. Já vendeu várias partes da área. Há vários processos contra ele na Polícia Federal, no Ministério Público Federal por conta de estar vendendo partes da terra. Na etapa de desintrusão, esta pessoa é uma das que está para ser expulso da área. Maria Geralda fez vários boletins de ocorrência contra ele. Ele, por sua vez, já ameaçou Geralda e sua irmã de morte. 
Disponível em: www.revistafenix.pro.br

$\mathrm{N}$ usa do fato de ser morador para tentar barrar o processo, reclamando supostos direitos de propriedade a parcelas do território do Rosa. O argumento que utiliza para tentar legitimar esta pretensão é o discurso do herdeiro: de que, por relações de parentesco distantes, é herdeiro destas terras e tem direito a elas.

A comunidade do Rosa enfrenta, assim, como outras comunidades, obstáculos internos no processo de etnogênese, no qual sujeitos vivendo no território da comunidade opõem-se ao processo de titulação, por alimentar interesses diversos da comunidade; e agem obstruindo o processo de titulação como podem, e tentando influenciar outros moradores a se opor à titulação.

Outra realidade é a dos moradores pertencentes de fato à comunidade, que tinham dúvidas no início quanto ao auto-reconhecimento como quilombola.

Na comunidade do Rosa havia o caso de Josefa, tia de Joelma e irmão de Maria Geralda, que não queria no início tornar-se quilombola, porque entendia que fazendo isso ela não poderia continuar com hábitos que tinha como caçar, e caçar e vender o produto da caça.

Josefa também tinha receios quanto ao tornar-se porque ouvia de outras pessoas, que eram contra o reconhecimento quilombola, palavras pejorativas, como "que ser quilombola era um atraso".

Josefa só mudou de posição conforme Joelma e Geralda explicaram para ela como era o processo. Sobretudo lhe esclarecendo sobre as interdições que haveriam, que não incidiriam nos hábitos alimentares ou de reprodução econômica; as interdições incidiriam apenas sobre a proibição de vender ou alugar.

Mesmo assim, é muito difícil falar que um processo de convencimento esteve em curso. O Rosa tem uma ética própria quanto à prescrição do posicionamento correto em relação às decisões que cada um toma na vida. Conforme expresso num dado momento por Josielson, o ato de convencer alguém de algo ou seu inverso, desaprovar decisão de alguém, são atitudes que não têm sentido no universo da comunidade.

Ninguém influencia ninguém. Cada um é dono de sua consciência. Aqui o que a mamãe fala a gente segue. E ela esteve decidida desde o começo. Eleanor disse 'se a minha comadre Geralda quer, eu também quero". Josefa esteve inicialmente em dúvida, porém depois juntou-se às irmãs. Aí só depois que as três vieram e bateram o martelo, que a gente foi atrás. 
Disponível em: www.revistafenix.pro.br

Não há o trabalho de convencimento de uns sobre outros, porém isto não exclui a influência do prestígio de uns sobre as decisões dos demais. No caso, especialmente o prestígio de Geralda é decisivo. A "obediência" se dá por iniciativa dos demais em torno das decisões de Geralda.

Há algo ainda a dizer sobre as dúvidas e hesitações da comunidade. Tanto o desconhecimento do direito e da lei pelas classes populares quanto a produção intencional de informação falsa, movida pelos detratores do movimento quilombola e do movimento negro, alimentada não só por interesses contrários à titulação quilombola como pelo racismo, foram, no período de auto-reconhecimento do Rosa, e ainda são no Amapá obstáculos a serem enfrentados no sentido do exercício pleno da cidadania das comunidades remanescentes quilombolas locais.

No Brasil, na luta simbólica as elites produzem deliberadamente conhecimento falso - ou desconhecimento - sobre a constituição e as leis em geral do país, objetivando afastar as classes populares da luta por seus direitos e do exercício pleno de seu direito e sua cidadania.

O efeito sobre a vida da comunidade desse obscurantismo produzido é assim expresso por Josielson: "Não sabíamos o que era quilombo. Naquilo que a gente estuda na escola não fala nada disso. Fala só dos bandeirantes atrás dos pretos. A gente foi saber o que era isso só agora, após muita luta, e que o INCRA teve essas atuações”.

Esta produção de desconhecimento e obscurantismo é fator pois adverso às etnogêneses quilombolas. Superado, todavia, pelo Rosa. Sua superação, como vemos, exige um intenso trabalho educativo pelas instituições e movimentos sociais ligados à causa. É um trabalho educativo e também luta simbólica, uma vez que não se trata apenas de oferecimento da informação correta, como também de combate ao preconceito produzido em torno da questão.

Apenas a título de comparação, a dialeticidade presente os processos de etnogênese é descrita também por Ratts (1999), ao analisar a configuração do território indígena Almofala dos Tremembé.

O autor, apesar de não trabalhar com o conceito de etnogênese, analisa um processo de afirmação étnica como os das etnogêneses, no qual a comunidade afirma sua identidade étnica, e, numa situação de contato adversa aos direitos étnicos, tem de criar mecanismos para consolidar e legitimar esta identidade face aos seus adversários. 
Uma conflitualidade interna à comunidade na construção da etnogênese é assim identificada por Ratts: “As vozes dos índios, captadas em contexto recente, plenas de metáforas de sua continuidade, indicam também processos de mudança e até mesmo a dificuldade de dar sequência a certas tradições” (RATTS, 1990, p.76).

No bojo de uma etnogênese, pois, as vozes da comunidade expressam ao mesmo tempo continuidades com o passado e mudanças no presente: este a primeira conflitualidade; a segunda, a dificuldade manifesta em manter dadas tradições, o que, no plano mais superficial, depõe - na relação inter-societária colonial e racista - contra a própria etnogênese - mas somente no plano mais superficial, uma vez que não significa nada para a autenticidade do processo.

O segundo elemento da dialeticidade, mais profundo por assim dizer, trata-se do que Ratts denomina sobreposição de ritmos. "É fundamental tentar interpretar essa sobreposição de ritmos para não correr o risco de encapsular os Tremembé (e outros povos indígenas [e comunidades em geral, incluso quilombolas] em situação semelhante) em duas temporalidades: antes e depois da emergência [ou da etnogênese]" (RATTS, 1990, p.76).

A etnogênese, ou a emergência na linguagem de Ratts, não é feita de modo estanque, nem com uma única ruptura absolutamente definitiva; não sendo linear, neste processo há uma sobreposição de temporalidades e de ritmos. O processo, por constituição, e não por acaso, é dialético.

\section{CONSIDERAÇÕES FINAIS: ETNOGÊNESE E TERRITORIALIDADE}

Não obstante a dialeticidade interna do processo, e as inúmeras forças externas contrárias à efetivação da cidadania quilombola, o Rosa tem se firmado como quilombo.

Uma força motriz decisiva para a intencionalidade da comunidade do Rosa em direção ao auto-reconhecimento como quilombola e o amparo respectivo da lei foram as ameaças reais ao território da comunidade, experienciadas no período. No que concerne à relação entre etnogênese e território, o auto-reconhecimento como quilombola e o posicionamento público como tal foi decisivo para assegurar o território do grupo face estas ameaças externas do período.

Pela análise deste processo recente protagonizado pelo Rosa sou levado a discordar de alguns supostos da literatura sobre etnogênese. Gostaria de observar que a 
Disponível em: www.revistafenix.pro.br

etnogênese é um fenômeno territorial, não identitário. Ninguém duvida que seja sempre uma transformação identitária; porém como sempre traz consigo uma pretensão territorial, é plausível questionar se a dimensão visível da etnogênese não seja apenas a consequência ou o invólucro de uma transformação - esta sim, verdadeira motriz do processo - de ordem territorial. A essência da etnogênese é, pois, territorial, não identitária. Isto se confirma também pela sua negação. As comunidades que têm assegurado seu território por outras vias, não iniciam processos de etnogênese na esfera simbólico-cultural.

A etnogênese é assim, em suma, um processo de dinâmica interna relativamente autônoma; porém, quando concebido na totalidade das relações sociais em que tem existência, é sobredeterminado pelo processo de territorialização que lhe deu nascimento.

Sobre a relação entre comunidade e identidade gostaria também de acrescentar algo que ainda não foi discutido na literatura sobre o tema. A comunidade não é sua identidade. A comunidade, com sua história, sua tradição e sua ancestralidade, é uma totalidade muito maior que sua identidade. A identidade não define a comunidade. Aquela é apenas um elemento na totalidade desta.

O procedimento de tentar, conceitualmente, reduzir a comunidade a sua identidade, ou definir a comunidade por sua identidade, é uma busca equivocada do ponto de vista conceitual, e de má fé do ponto de vista político. Compreender que a comunidade é uma entidade muito maior do que a identidade que apresenta, com que se apresenta ao exterior, no contexto multiétnico de contato, e com que o exterior a lê, é o passo necessário a ser dado neste momento para compreensão científica das comunidades quilombolas, de sua ontologia e de sua historicidade real.

\section{REFERÊNCIAS BIBLIGRÁFICAS}

BARTOLOMÉ, M. A. As etnogêneses: velhos atores e novos papéis no cenário cultural e político. Mana, v. 12, n. 1, p. 39-68, 2006.

JORGE, A. L.. O movimento social quilombola: considerações sobre sua origem e trajetória. Vértices, Campos dos Goytacazes/RJ, v.17, n.3, p. 139-151, set./dez. 2015, p. 146. 
PEREIRA, Edir. Resistência descolonial: estratégias e táticas territoriais. Terra Livre, São Paulo, 2017, Ano 29, Vol.2, n 43 p.17-55.

RATTS, Alecsandro José Prudêncio. Conceição dos Caetanos: memória coletiva e território negro. Palmares em Revista. Brasília. No. 1, 1996, p. 97-115.

RATTS, Alecsandro José Prudêncio. Almofala dos Tremembé: a configuração de um território indígena. Cadernos de Campo, 8, 1990, 61-81 